\section{Discussing 'Genre' in Anime through Neon Genesis Evangelion}

Manuel Hernández-Pérez

\section{Introduction: Authorship and Genre as Foci of Approach}

The worldwide distribution of Neon Genesis Evangelion (1995-96) had a significant impact on the audiences for anime markets. However, unlike previous TV anime megahits, such as Dragon Ball (I985), EVA distribution in Western countries started in domestic and young adult markets. The series gained its reputation in a period of transition between VHS and DVD formats and even managed to be successful on a new route for anime: from niche video markets to thematic TV channels through small broadcasters and cable stations.

That was the case of EVA distribution across the United States, at that time already one of the main markets for anime overseas. The series began to be distributed in June 1998 for the VHS market (A.D. Video), although it wouldn't be broadcasted on TV until 2002 (KQEH), being later offered by other theme-specialized channels such as Cartoon Network (through the special event 'Toonami's Giant's Robot week' broadcasted in February 2003) and Adult Swim (October 2005). EVA distribution in France (1996), Italy (I997) and Spain (I997) followed a similar strategy, as it was distributed first as a video product rather than being broadcast to general audiences. Most of the time, the series was dubbed to the domestic language, except for France, where it was distributed in Japanese with subtitles. This was due, perhaps, to its early release (I996). The distribution in Australia (I998) and Southeast Asian markets such as the Philippines was different as ADVision didn't manage the copyrights for these markets. The main agent of distribution was the main national broadcasters instead. The franchise would arrive
How to cite this book chapter: Hernández-Pérez, M. 202I. Discussing 'Genre' in Anime through Neon Genesis Evangelion. In: Santiago Iglesias, J. A. and Soler Baena, A. (Eds.). Anime Studies: Media-Specific Approaches to Neon Genesis Evangelion. Pp. I8I-2I4 Stockholm: Stockholm University Press. DOI: https://doi.org/ıO.I6993/bbp.g. License: CC-BY 4.0 
I. See Chapter ro by Jessica BauwensSugimoto.

2. See Chapter 8 by Olga Kopylova on types of fan readings. in Central and South America some years later, only for cable and satellite thematic channels (Canal 22 Mexico, 2007; Animax for Latin America, 2008).

At the end of the 2oros, the initial EVA series had apparently achieved the status of a cult product. Internet streaming services made possible its access to a much wider and, arguably, global audience. The worldwide release of EVA on Netflix (2019) has introduced this series to new international audiences for the first time. Netflix's global broadcasting has also highlighted the historical significance of this series in national markets already familiar with the franchise. The response of these markets, influenced by nostalgia, has not always been positive though. There have been many examples of controversy, including complaints about how new translations of the script and subtitles hide key plot elements, such as the homoerotic subtext of the story. ${ }^{1}$ Besides, the redubbing of the series in several countries, casting different actors, has been read as pure 'betrayal' by fan audiences. Also, limitations of copyrights have contributed to this disappointment and resulted in a modified version of the ending without the different covers of the well-known I954 song Fly Me to the Moon. While it is not always easy to identify the voices behind social media, primarily fan audiences seem to be suspicious about the new Netflix version, due to their long-term emotional investment.

Discourses on EVA have extensively highlighted its uniqueness when comparing the series to other anime series from the same period. One of the factors behind this is the complexity of its plot and certain lack of closure, due to its open ending (or even 'endings' if we take into consideration other paratexts). Social media is full of reviews and deconstructions of the series, performed by fans. ${ }^{2}$ While these discourses may involve different communities, EVA's uniqueness is usually constructed through comparison with other examples, that is, similarity among a group of texts, which share a common 
property based on material, rhetorical or semantic properties. In a later step, the similarity among the members of this category allows the differentiation from members outside the definition criteria.

Therefore, readings of EVA and its uniqueness usually fall into highlighting the belonging to these categories, a conceptual strategy also known as 'genre classification.' An alternative reading is authorship, which is a common construct to attribute the unique style of a product to the personality of its main creator(s). Readings of EVA have often been oriented at the personality of Hideaki Anno, the filmmaker responsible for the series' script and direction. However, collaboration played an equally important role during the production and pre-production processes:

The impression of 'Live' concert that gives me the birth of Eva, was the team joining me in developing it, in the manner of an improvisation: someone plays the guitar and, in response, the drums and bass are added. The performance ended with the TV broadcasting end. We only started working on the next script once the previous one was done. (Anno I996b: I2)

Anno's strong personality has been emphasized by many as the main reason for the series' singular style and narrative (Azuma 20I6; Watanabe 200I: I48). But, as in other cases of authorship in the world of Japanese anime, personality as an author takes the form of 'persona,' a mask (Hernández-Pérez 2016), and this can easily shadow other readings of anime as a collaborative medium. Anno himself has contributed to the construction of this mask through numerous paratexts, such as biographical and autobiographical notes, interviews and media reviews. Probably, the most obvious example of cultural criticism inspired by biographical paratext can be found in psychoanalytical readings of EVA's plot:

On its deepest level, Evangelion has become inseparable from the life of its creator, Hideaki Anno-and from the arc of coming to terms with his (and the audience's own) lifelong struggles with depression and 
alienation, and how they often lead us to seek refuge and withdraw into inner landscapes of the imagination. But this pillar of culture all starts with a few nerds in one small room, and Anno, a brilliant prodigy among them. (Stewart-Ahn 2019: para. 5)

Anno himself may have contributed to this mystification by statements such as the following:

Evangelion is like a puzzle, you know. Any person can see it and give his/her own answer. In other words, we're offering viewers to think by themselves, so that each person can imagine his/her own world. We will never offer the answers, even in the theatrical version. As for many Evangelion viewers, they may expect us to provide the 'all-about EVA' manuals, but there is no such thing. Don't expect to get answers from someone. Don't expect to be catered to all the time. We all have to find our own answers. (Anno I996a: 20)

Reading media texts through authorship is a common strategy shared by general audiences, fan communities and professionals. However, in Media Studies, and especially in Film Studies, the term has a particular history of debate and confrontation. Authorship implies that audiences can identify a signature, corresponding to an individual or group of individuals, behind a media product. It has been noted that in media industries it is possible to identify different kinds of authorships, either multiple, collective or even corporative (Dyer I998: I 5I). While the work of the professionals involved in a production is always necessarily collaborative, 'multiple authorship' differs from 'collective' understood as the identification of different

3. Production Committees are subsidiary companies created to produce and distribute a particular anime. They may include copyright holders, TV broadcasters, anime producers and toy manufacturers. Usually, both manga creator and production committee are identified as co-owners of these copyrights. works rather than a single complex artistic piece. In manga, collective authorship (if acknowledged at all) applies to the artist, or mangaka, and the editor, while in anime adaptations of manga, authorship and copyright tend to be distributed between the mangaka and the production committee. ${ }^{3}$ In the case of EVA, it is not difficult to consider multiple authorships. In that sense, the series proposal, written in I993 and employed with promotional purposes, identifies Hideaki 
Anno as director and writer, Yoshiyuki Sadamoto as character designer and Ikuto Yamashita as mechanical or mecha $a^{4}$ designer, which are all common and main roles within anime productions (GAINAX I997: 86). Arguably, corporative authorship also played a significant role in the international distribution of both EVA and post-EVA products. Studio GAINAX, famously created by a group of enthusiasts, had been a well-known brand, but it didn't start recovering from its initial debts and gaining nationwide fame until the EVA success (Takeda 2005: I32). Anno left GAINAX in 2006, with the goal of releasing the tetralogy of NGE Rebuild films with his new Studio Khara (Studio Khara 2006).

While authorship has been related to the uniqueness of a media text, the designation of a genre tends to be associated with the limits of authorial creativity. Criticism addresses this constraint when defining the prescriptive use of genres, the so-called producer's game (Altman I999: 38), which devalues the work of creators to identify successful formulas. In the case of EVA, it is the similarity to other productions in the Super Robot, or Mecha Genre, whose conventions are usually employed as criteria to measure its originality. However, while authorship and genre seem to be opposing terms, in fact, many authors find their stylistic and thematic approaches to be linked to a particular genre (Feuer I992: I43), as identifying their work with a particular genre could be a creative choice in itself. That is the case of Anno and EVA, a work that is defined by its uniqueness but that still employs genre in constructing a framework to interact successfully with producers, distributors, and global audiences.

In this chapter, I will focus on how the EVA anime and franchise can be categorized with regard to genre. I will start with a focus on narrative contents, primarily, the main tropes of mecha anime. However, this may not be enough to define and identify genre categories properly. As I will demonstrate, EVA feeds on multiple genres, including traditions of Science Fiction (SF), the Japanese Special Effects
4. Mechanical Designers are artists specialized in the illustration of technologies and are usually associated with the Super Robot Genre, also known as mecha. Due to the well-known synergies between the toy industry and anime, this figure became essential in the design of mechanical characters that can be adapted to toys, plastic model kits and other forms of merchandise. The first artist signing as mecha designer was Kunio Okawara (b. I947), who was responsible for Mobile Suit Gundam (Kidō Senshi Gandamu, I979). 
TV shows (tokusatsu) and the Monster Films (kaijü eiga), as well as other Japanese TV anime. Actually, the different ways of addressing the relationship between EVA and the concept of genre, including authorship readings of anime, are at the heart of this chapter. It sets out to demonstrate the role that Genre Studies can play in Anime Studies and the challenges behind the cross-media and transmedia conceptualizations of genre. Eventually, it is expected that these strategies can facilitate Anime Studies through the lens of Cultural Studies and Media Studies.

\section{Discussing EVA from the Perspective of Genre}

The term 'genre' refers to the creation of categories and groups of texts. Genre theory had a long tradition in literary studies before it started to be employed in the context of Media Studies. There's a considerable corpus of work about genre in Film Studies (Altman I999; Wood I998) and TV Studies (Feuer I992; Mittell 200I). This chapter leans mainly on TV Studies, assuming some material and structural features in anime to be similar to other broadcasted serial products.

Genre categorization implies the differentiation of a whole set of elements combining various historical and also textual approaches. In Media Studies, for example, genre is employed when the production of a specific period or by specific creators is identified with regard to the recurrent use of archetypal characters, a particular set-up, iconography, narrative content or style and the casting of screen celebrities. It is easy to see the fallacious logic of genres. Once the labels are established, they will define the product and all of its 'family' due to resemblance. But discovering new exemplars will defy the integrity and identity of this group. Jacques Derrida responded to this dilemma and denied the need for any text to belong exclusively to a category, a prerogative coined as the 'principle of contamination': 
With the inevitable dividing of the trait that marks membership, the boundary of the set comes to form, by invagination, an internal pocket larger than the whole; and the outcome of this division, and this abounding remains as singular as it is limitless. (Derrida \& Ronnel I980: 59)

Derrida's ideas point to a new, more complex conception of textuality and the singularity of artistic production. However, this singularity can be read not only as an exclusively textual property of each work of art, but also as a property that emerges from the dynamics of a particular set of texts or discourse. Genres are embodied in texts and discursive practices. Mittell reminds us that "there is a crucial difference between conceiving of the genre as a textual category and treating it as a component of a text, a distinction most genre studies elude" (200I: 5). His cultural definition of TV genres is articulated through several paratexts and discursive practices involving industry and audiences.

Following these ideas, many authors disengage from a strict vision about texts belonging to a particular genre. They assume that films are, first and foremost, hybrid or transgeneric products, as they always combine elements from different genres (Altman I999: 53). Therefore, genres are constructs that designate not only a set of texts, but the properties of a given text. They can change and mix. Adopting a strategy of hybridization is a common feature in all media products.

While there's a wide range of genre theories, scholars have questioned the utility of genre as an evaluation method, regarding its problematic reflexivity. Genre is usually employed to select a group of texts. However, the main interest of the researcher would be, precisely, to prove that certain texts belong to the predefined group. Since, as noted by Feuer (1992: I08), the formation of categories responds to arbitrary decisions, rather than induction or data collection, research methodology is compromised.

Anime Studies require defining genres from historical, cultural, discursive and even ideological perspectives. As I will demonstrate, 
cultural criticism and academia link the EVA TV series to the tradition of mecha anime, while EVA authors, including Anno, usually refer to the influence of other genres, for example, Speculative Fiction. Defining the textual properties of a genre would be the first step, while identifying the interrelation of EVA with other generic forms is also necessary.

\section{Historical and Cultural Approaches to Anime Genres}

Genres are constructed by the images that audiences and creators have about large groups of texts. Film genres have been traditionally defined through a process of authoritative deduction, resulting from the work undertaken by the community of cultural critics curating films from a specific period, and this classification becoming eventually accepted by audiences and producers.

Anime industries, on the other hand, have been defined in terms different from cinema and animation. Publishers' definition of demographic sectors was employed as the main classification for manga and later extended to anime products. Taxonomies traditionally correspond to the potential readership of manga magazines, defined by age and gender. Thus, the Japanese publishing market distinguishes between four categories: kodomo (children), shōnen (adolescent boys) and shōjo (girls), seinen (initially aimed at young male adults) and josei (women). This classification only refers to the potential audience of the product. It says little about textual or material properties. As a matter of fact, there is a mismatch between demographic genre labels and actual audiences. These taxonomies become arguable when thematic labels such as sports (supōtsu) or communicational purposes such as educational (gakushü) are also employed as subgenres. There is significant criticism toward the idea of assimilating such different conceptualizations of genre at the same time. For example, it has been pointed out that there is a historical trend to hybridization not only among the products originally addressed to demographic sectors, but also in the diversification of thematic labels (Yamaguchi 2004: I04-IO6). 
At first glance, EVA may appear as a text belonging to the demographic genre of shōnen. This applies, for example, to features of its narrative setting, such as the school life subplot, the use of teenagers as main characters or the considerable amount of battle scenes involving monsters and piloted robots (mecha). However, Anno declared to have had an adult demographic target in mind (over 30 years of age), while acknowledging that some concessions were made, such as the introduction of female characters, to make the product more accessible to (male) fan audiences:

You need to understand that Japanese animation is an industry that is, for the most part, male, and as is quite evident, everything is made for their gratification. Further, it is more gratifying for us to draw this sort of character, rather than old grandmothers. (Anno as quoted in Giner 1997: 19)

Furthermore, some manga adaptations of the original TV anime notably shifted with regard to target audiences. Sadamoto's Shin Seiki Evangelion (NGE) was originally serialized in a shōnen magazine (Monthly Shōnen Ace, I994-2008), but continued in a seinen publication by the same publisher (Young Ace, 2009-20I4). This appears exceptional, as anime-to-manga adaptations usually hold on to the initial demographic target, which applies also to the aesthetics of the source text, its main plot and its premises. On the other hand, despite the existence of several paratexts such as interviews, making-of and talks recorded at comic conventions, there are no statements by the EVA creators that point out any generic definition of the franchise. This contrasts with the references by Anno and other initial GAINAX members to anime titles and novels in the SF genre tradition.

Historical, cultural and even ideological approaches to genre categorization should be understood as part of shared constructions among professionals and creators. A necessary condition for this is the self-acknowledgment of genre elements and formulas that starts with their informal analysis, or mere consumption. The creators learn these formulas and incorporate them into their own practice, as implied by 
Thomas Schatz when he describes the transformation "from straightforward storytelling to self-conscious formalism" (Schatz I98 I: 38 ). Thus, genre must necessarily be discussed with regard to textual properties and be differentiated concerning stylistic and narrative elements that may indicate affiliation, in the case of EVA, shōnen, mecha and SF.

\section{Textual Approaches to Anime Genres}

So far, I have discussed approaches to anime genres as historical or cultural categories. However, while considering genres as categories, they are still texts or, more specifically, a group of texts, and their textual features are almost inseparable from those aforementioned classification practices.

At this point, it may be necessary to clarify that anime is not a genre. Many scholars consider anime a medium (Hu 2010; Napier 200I) that is defined by its own language. Genres constitute a set of media texts based on familiarity or resemblance with a particular tradition. Some scholars try to define anime with transformations of the term genre, such as a transnational meta-genre (Denison 20I 5: 24). While there's goodwill in defending the diversity of anime acknowledging, at the same time, its identity as a common set of narrative, cultural and stylistic conventions, this categorization seems unnecessary. For anime is rather a medium, as stated above. And medium is a valid category to define the embedded physical, cultural and historical properties (Ryan 2004: I6).

Traditionally, textual definitions of genre differentiate between semantic and syntactic elements in reference to Altman (I999: 89) and his dual conceptualization of genre. Semantic approaches refer to those elements that are most noticeable. This idea is extended by iconographic approaches to genre (Buscombe I970; Grant 2007) which maintain that even isolated elements can be associated with a particular genre. Syntactic definitions of genre refer to the meaning 
emerging from the relationships between these elements. Syntactic approaches have found that the extensive use of particular plots and subplots, or 'formulas,' is enough to identify genres such as Film Noir or Adventure Movies (Cawelti I976). In addition, style can contribute to the identification of genres, but it is not addressed specifically by Altman (I999), who seems to consider it to be part of the iconography and, therefore, of semantic reading.

Audiences may identify a particular form or language resource and, subsequently, realize the meanings that emerge from the associations between the codes employed (Altman 1999: 38). Anime formulas or clichés, for example, do exist and are usually associated with particular demographic genres. Semantic approaches to manga and anime have reduced genres to narrative contents. Regarding this, mecha is one of the most distinctive genres within manga and anime (Bryce \& Davis 2010: I7; Drazen 2003: 240). Therefore, it could be a categorization similar to that of shonen, designating a tradition with well-identified semantic and syntactic features.

\section{Of Mechas and Monsters: EVA within Genres}

The mecha genre's central trope was introduced by Gō Nagai's Mazinger $Z$ (1972), which arguably featured the first piloted robot in manga. Mecha designers and mecha animators are established professions in the industry and, arguably, highly influential in the success of any franchised intellectual property, as their design may inspire different kinds of toys. Anime in particular and Japanese popular culture in general show a fascination of writers and designers with humanoid robots. Robots are usually linked to other anthropomorphic representations of technology or mechanics whose presence in popular culture dates back to kamishibai. Within the industry, creators use 'robot' as an umbrella term for all kinds of artificial bodies, while others within SF communities tend to differentiate between cyborgs, androids, (real) robots and piloted vehicles (aka mecha). 
It seems somehow inappropriate to regard mecha as a subgenre of shōnen. While both can easily be traced in terms of authors, stylistic conventions and traditions, shōnen is a demographic classification and mecha a mere thematic one. Connections between shōnen and mecha themes are usually expressed with the 'boy and robot' label (Poitras 200I). This is a dual form that, in fact, reflects the animist motivation behind mecha narratives. Mecha characters facilitate safe drama, providing these narratives with a character that can be repaired at the end of each episode or season. In this sense, the mecha genre accommodates sacrificial heroes who aren't really alive, but are still able to reflect the audience's and their pilot's emotional states. Many media texts for adult audiences incorporate such projection of human emotions onto real robots and mechas, for example, anime inspired by the work of Masamune Shirow, such as Patlabor: The Movie (1989) and Appleseed (2004).

While mecha is assumed to be a quintessential Japanese genre (Wong 2010: 332), the idea of using piloted robots for military purposes was already a common topic in Western SF. Robert Anson Heinlein introduced in his Starship Troopers (1959) the concept of the exoskeleton or mobile suit, a robotic armor that allows the increase of the pilot's combat skills. Although far from being as influential as Osamu Tezuka and Mitsuteru Yokoyama's robots in Japan, the work of Heinlein had a considerable impact after its translation in 1967. The similarity of the Japanese illustrations from the I977 edition with Kunio Okawara's mecha designs for Mobile Suit Gundam (1979) has attracted attention (Tatsumi \& Bolton 2008: I92). Other Western influences, mainly Thunderbirds (I965-66), have been emphasized by cultural criticism and academia. In this TV series, as in many other works by producer Gerry Anderson, technological and futuristic designs play a crucial role. However, Anderson's SF productions, addressed to young audiences, may have had more influence in terms of style than characters. While Thunderbirds does 
not feature robots, it introduced the 'transforming/combining' features so characteristic of robot anime (Hikawa 2013: IO), popular transformation scenes common in both Tokusatsu TV shows and Magical Girl anime.

The main narrative of the EVA TV anime is articulated through episodes featuring spectacular battles among monsters and giant robots. Purportedly, Anno's only interest was the renewal of mecha genre, despite some statements that have linked EVA to the Tokusatsu tradition (particularly how Ultraman (I966) may have inspired the Eva units). Producers pitched EVA as a Super Robot anime:

The protagonist is but an ordinary boy one could find just about anywhere. Until now, the pilots of giant robot animation have all had natural ability and talent from the start. That unique hero is one children aspire to be, and is someone they relate to. (NGE Proposal, extracted from GAINAX I997: 85 , translated by EvaWiki)

Interestingly, the Eva units do not faithfully reference the mecha genre, but rather divert from this tradition. They seem to have their very own emotions. ${ }^{5}$ They are living beings, creatures cloned from relatives of the protagonists themselves, a narrative turn that justifies the intimate bond which, at the subconscious level, seems to exist between pilots and Eva units. In fact, regarding the tradition of SF literature, Eva units would be cyborgs or modified humans instead of robots. Ikuto Yamashita was the mecha designer for EVA and responsible also for the visual development of previous GAINAX works such as Gunbuster (Aim for the Top!, I988) and Nadia: The Secret of Blue Water (Fushigi no umi no Nadia, I990). Yamashita's design has been described as more organic and curvier than the typical linear forms and metallic textures used in traditional mecha anime (Cavallaro 2009: 66). As remembered by Yasuhiro Takeda, GAINAX's General Manager of Animation Production (I984-20I6), Yamashita's organic designs challenged the mecha genre conventions since the early stages of the project's development:
5. See Chapters 2 and 5 by Ida Kirkegaard and Stevie Suan, respectively. 
(Toshimichi) Ôtsuki brought the proposal to a certain unnamed toy company, the guy there told him a robot with a design like that would never sell. He said the legs were too skinny, and then proceeded to give Ötsuki a lecture on the principles of robot design. (Takeda 2005: I67)

Mecha designs in EVA work at a semantic level, but also ignite syntactic readings that ultimately connect with meanings usually related to other narratives. Anno highlights the influence of Nagai's work, particularly his manga Devilman (I972), as inspiration for the Eva units. We should remember that, regarding the main storyline, the Eva units are clones of the first Angel, Adam. Their designs are, therefore, an alternative version of what humanity (also Adam's children) could be. This is acknowledged by Anno himself:

There is a monster in Japan called the oni, which has two horns sticking out of its head, and the overall image of the EVA is based on that. I wanted also to have an image that beneath the image of that robot monster is a human. It's not really a robot, but a giant human, so it's different from other robot mecha such as those in Gundam. (Animerica I996: para. 3).

On the other hand, it is a known fact that the EVA creators were avid consumers of SF products. Anno is a big tokusatsu (specialeffects cinema) and SF consumer. In I983, still a student, he and other members of Daicon Film, the seeds of the future GAINAX, created a fan film by the name Return of Ultraman. In recent years, it has been common to find Anno participating in specialized forums, such as conventions, special screenings or live talks (Chapman 20I7: para. 3). In his role as an expert, he has even directed the Media Bunka report focused on the history of the tokusatsu genre (Anno \& Higuchi 20I3).

There are semantic and syntactic relationships between tokusatsu, its monster imaginary and the mecha tradition that can be directly observed in EVA. After all, one of the first mecha series, Mazinger $Z$ (I972), follows the formulaic journey of fighting a monster every week. This connection is also reflected in the idiosyncratic 
manufacture of these television shows and their 'texture' (Anno \& Higuchi 20I3: II), a syntactic element that is arguably transferred to EVA. Despite being live-action shows, tokusatsu products are, in fact, all about their monsters. The main difference between tokusatsu and stop-motion is purely performative, since most Japanese shows tend to use masks, costumes and make-up (a set of tools described as 'suite motion') instead of stop-motion techniques. In this sense, the EVA franchise creators have pointed out how the original premise was to create a remediation of a tokusatsu and mecha serial with a twist based on subjectivity:

Up until that time, there had never been an anime about gigantic robots battling these mysterious monsters invading the planet, while at the same time focusing on what was going on in the minds of the main characters. (Watanabe \& Otsuki 2006: para. I2)

EVA receives influences of all these genre traditions, borrowing characters and even plots from tokusatsu or kaijū cinema ${ }^{6}$ and mecha narratives. However, the relationship of EVA to these genres is one of hybridization. Those narrative tropes have migrated across genres and media. Since one of the main notions of the genre is aesthetic (Feuer I992: I09), the interrelation between EVA and these influences can no longer be intertextual, but it is necessarily intermedial or transmedia. The aforementioned hybridization of mecha and tokusatsu traditions within EVA is a result of a transmedia adaptation of iconography. Anno went on to pursue these interconnections in the live-action film Shin Godzilla (20I6), a remake of the classic kaijū movie, co-directed with Shinji Higuchi.

\section{Exercises in Intertextuality and their Semantic Readings on Genre: Is EVA an SF Anime?}

Some genres are easier to define from a semantic perspective than others due to their most identifiable spatial and temporal settings. That is
6. Kaijū (monster beast) eiga refers to a group of serial nature movies starring giant monsters. Inaugurated by the iconic Godzilla (1954), its homogenous style and narratives, combining spectacular visual effects, the destruction of urban environments and its effects on the characters all have their legacy in the later Disaster Films of the I970s and I990s (Napier I993: 328). 
the case with SF stories, which many audiences associate with a set of particular iconographic elements (spaceships, aliens, etc.), narrative formulas (time travels, man-made creatures, etc.) or the creation of idiosyncratic images that work as focal points of their narratives (distant uninhabited planets, monumental star ships, lonely laboratories). However, after the recognition of semantic and syntactic elements of a genre, there is yet another level of decoding for the audience: the recognition of intertextual relationships among products in terms of family resemblance, a process that structural narratology denominated architextuality (Genette I992: 83).

SF forms a group of texts with a long tradition in Literary and Media Studies and, yet, it is still often subjected to the controversy concerning its definition as a genre. SF involves the creation of fictional worlds that are perceived as plausible. Some authors have discussed the potential semantic mechanism that identifies these parallel worlds in contrast with other fictional stories. SF narratives, for example, introduce a bridge to avoid 'cognitive estrangement' in the reader's mind, a so-called novum that is accepted implicitly by the audience (Suvin I972: 373). The novum usually takes the form of technological innovation, but, in the logic of SF, this innovation creates a chain of technological, cultural and, ultimately, social consequences that shape the new world and characters' psychology. The novum is exclusive to SF, while the fantasy genre lacks this element and, even more importantly, dispenses with the construction of a chain of consequences. In contrast with SF, speculative genres such as fantasy or horror may also create coherent worlds, but their narratives are not intended to explain those rules. SF is based on the dialectics of these 'estrangements' and the appeal to the reader's 'cognition' (Suvin 1979: 7).

Referring to SF as a 'genre' is rather conservative, as distinct from regarding this corpus of texts as a tradition. SF responds more to the idea of a set of genres, or a genre colony, a term originally coined to describe the interaction between different genres that are serving the same communicative goal (Bhatia I999: 29). There is a SF colony, 
which through its many different genres across media (novel, TV series and so on) shows formulas and tropes of great persistence.

This has contributed to its capacity for transmedia expansion (Jenkins I992). And all these SF narratives would have in common the presence of a novum, although some other genres, even those developed in different media, could be part of what has been called 'family' due to their resemblance (e.g., the television space opera, the 'soft' SF novel or the superhero narratives in comic-books).

SF has been frequently employed as a framework to read Japanese popular culture as a whole. The fact that a generation of Japanese authors experienced the consequences of war has led to a large number of readings of Japanese SF as post-World War II narratives (Orbaugh 2009: I I2; Watanabe 200I: I20). However, those narratives have been, at the same time, linked to the Japanese predilection for 'disaster' narratives and dystopia (Napier I993: 329).

As often happens with explorations on genre, semantic accounts are easier to perform. Studies have pointed out a relevant number of anime framed as SF narratives, especially in relation to artificial bodies, including robots and mecha (Bolton \& Csicsery-Ronay 2007; Orbaugh 2009: I I9). There are, however, also reasons to assume syntactic relationships between anime and SF, which are a consequence of this medium's specificity. Anime is different from other media such as animation or live-action film, as scholar Toshiya Ueno states:

In contrast, the technology and visual detail of animation in Japan is unusually sophisticated. With the exception of the gold or green color of characters' hair and the exaggerated shapes of their mouths and eyes, animation in Japan simulates reality to an excessive degree. (This is especially striking in reflections of light and water or the depiction of details in vehicles and mecha). It does not aim for the simple reproduction of reality but the hyperreality of things with no referent, things that are "more realistic than reality." (Ueno 2006: I I 2-II3).

With this statement, Ueno doesn't deny other visual styles within anime, such as exaggeration, but emphasizes hyperreality and thereby 
suggests the pedagogical value of anime. And what is SF but a pedagogy of alternate world's scenarios?

In the light of such considerations, is EVA an SF narrative? The EVA franchise's discourse collects references to the SF tradition or 'SF colony of genres,' and this manifests in two complementary facts. First, Western audiences tend to consider EVA as SF, in part, due to the characteristics of the spatial and temporal settings of the fictional world, like the plot set in a dystopian future. It is not easy, however, to identify the novum within EVA's narrative. Perhaps, the AT (Absolute Terror) Field, or shield that Evas and Apostles share, or the obscure technology of cloning behind the Evas could be the most likely match. There are, however, some examples of SF rhetoric in the construction of EVA's world. The technical requirements and infrastructures needed to move Eva units, for example, might have been the cause for the rigid militarization of Japanese society as depicted in EVA, as well as the compliance of its citizens who accept to live in an ongoing state of alert. It is technology behind the Eva units that vests an incontestable power to the government and makes the temporal and spatial settings adapt logically to the resolution of this dystopian alternate world scenario.

In summary, shared iconography through SF genres can be found in EVA, and there are elements of both estrangement and appeal to readers' cognition. However, other iconographies that populate the series connect with religious and, specifically, apocalyptic narratives. Perhaps those intersections can give us a better cue of genre hybridization in EVA.

\section{SF Meets Apocalypticism: The Nihilist Message of EVA}

EVA has been frequently described as a post-apocalyptic (Thomas 20I 2: 7 I) or apocalyptic narrative (Napier 200I: 29). The Apocalypse or Book of Revelations written by St John is a Christian canonical text 
that relates in future voice (prophecy) to the end of God's creation. As we know, EVA's narrative is the realization of an announced tragedy that will end, unless NERV can avoid this, in the Third Impact. The references to Judeo-Christian iconography may suggest that the EVA subtexts are readings of other Christian narratives (Ortega 2007). An author interested in millenarist readings of popular culture, however, denied that EVA's story was a genuine portrait of apocalypticism and described it as "scarcely more than mecha anime in apocalyptic dress" (DiTommaso 20I4: 484).

The rupture of EVA's linearity (especially in the last two episodes) can disorient audiences in a way similar to prophetic texts. Do EVA fans need to be initiated in their hermeneutics? Napier (200I: 193) designates the series as paradigm of what she defines as apocalyptic narrative mode, which she describes as one of the main narrative directions within anime. EVA may not be an apocalyptic text, but there is a clear apocalyptic mood behind EVA's plot. First, this is because of the historical relationship of apocalyptic or pseudoapocalyptic narratives with the genre of SF. Classifying EVA as an apocalyptic narrative would strengthen its participation in the SF colony of genres. Second, it can help to discuss whether the definition of a clear theme associated with a recognizable iconography can be the basis for a generic definition of texts, a strategy that we have identified as the semantic approach to genre.

Apocalyptic scenarios are quite common among SF. In the heart of its narratives, 'catastrophe' can be found, which is a mirror concept of the utopia projected by technological development (Mousoutzanis 2009: 458). The depiction of catastrophe can point to a moral message when SF narratives refer to the negative consequences of technologies. But apocalypse in SF usually lets the story begin after the catastrophe. In EVA, we have two scenarios. First, using Christian terminology, the story speaks of a 'Second Impact' which, like the 'Second Coming of Jesus,' presents the beginning of the End of Times. 
This event places the story in a catastrophic scenario: the arctic poles have melted, the temperature of the planet is increasing and the international relations among the economic powers have changed. Second, this catastrophe determines the narrative as it is followed by creatures called Angels. The rest of the story features efforts of the humans to stop world destruction, but they fail.

EVA's distribution overseas tried to create stronger links to SF through the translation. In the second episode, the 'Human Complementation Project' is translated as 'Human Instrumentality Project.' This incorporated a reference to the work of Cordwainer Smith (I993), an American SF writer and author of Instrumentality of Mankind, a collection of short stories originally published in I979. In Smith's fictional universe, this term is referring to his story-world, but it is also the name of the organization which controls different species derived from human beings across the galaxy. As such, his narrative shares some of the post-humanist subtext of the EVA anime, but it is difficult to find more similarities.

EVA constantly refers to Christian mythology, particularly the so-called eschatology or tales about 'last things.' However, such religious and spiritual aspects arise from its relationship with different traditions within SF rather than an explicit reference to the Christian tradition. Apparently, in Japan, the franchise has elicited some interest in cultural artifacts related to Christianity (Thomas 20I 2: 7I); however, this seems to have resulted more from the story setting and its inherent exoticism for non-Christian audiences. Kazuya Tsurumaki, assistant director of the series, distanced himself from any Christian reading of EVA:

There are a lot of giant robot shows in Japan, and we did want our story to have a religious theme to help distinguish us. Because Christianity is an uncommon religion in Japan we thought it would be mysterious. None of the staff who worked on Eva are Christians. There is no actual Christian meaning to the show, we just thought the visual symbols of Christianity look cool. (Tsurumaki interviewed by Thomas 200I: para. 23) 
EVA adapted Christian myths into familiar forms through a process of domestication. Drazen (2003: 360) pointed out, as an example, that the Spear of Longinous seems to reproduce the narrative of Izanagi and Izanami's Spear of Heaven. This domestication of narratives is also evident in the lack of linearity of the EVA story. While the Christian apocalypse corresponds to a linear conception of time, EVA, like many other anime, transforms apocalyptic tales and their inherent linearity into eternal cycles of reincarnation. These cycles of death and rebirth have been called 'apocalyptic' (Napier 200I: 193), but this may not be the right term. In EVA, the battle between good and evil is less important than Shinji's mental battle with his own anxieties. The anime series' ending that presents Shinji and Asuka is not so much a happy closure as a bitter new beginning without God and, in that sense, it breaks the expected linearity of apocalyptic narratives. EVA speaks to viewers about the end of the world. However, in the anime, the apocalypse stands in not only for social anxieties, but also existential concerns. The end of life and, therefore, of subjective experience manifests in an obsession with the transience of life, which ultimately creates nihilistic visions of existence which appear as criticism of technology (Napier I993: 330).

Within the series' storyline, there is no direct reference to the Gospels or the prophecies. Perhaps this is unnecessary. The symbiosis of SF and apocalypticism finds its justification in the fear of technology and human solitude, which are outcomes of a post-secular world. EVA more closely resembles an eschatological narrative, as it describes the end of things, an afterlife story. In that sense, EVA can be considered a text of spiritual nature, but it can hardly be regarded as religious as it doesn't establish an intertextual reference to religious texts, either by quotation, discussion, parody or adaptation. After all, EVA's lack of closure has always been part of the image that its creators seeked to project. 


\section{Discursive Practices on EVA Distribution and Consumption}

So far, I have explained the ways in which semantic (mainly iconography) and syntactic (intertextuality and the peculiarities of anime's visual language) elements of EVA may allow for a discussion of this series in terms of genre. However, both vocabulary and syntax would be only one, though significant, part of the genre equation. The consideration of common narrative tropes, settings or plot formulas, for example, could help, but genre is necessarily a result of a whole conversation between audiences and producers as well. This conversation will take place only when audiences identify codes as part of each genre's inner rules. Definitions of genre that put the focus on cultural consumption (Mittell 200I) have to be linked to practices of genre consumption, conceptualized as 'an exchange between industry and audience, an exchange through which a culture speaks to itself' (Feuer 1992: 109).

Anime audiences have been studied in relation to fan audiences or those with a higher level of engagement with their narratives. In this sense, EVA is closely connected to the otaku culture. ${ }^{7}$ The creators of the EVA TV anime have been linked to this movement by their first works, which came into being before their professionalization. That is the case of Otaku no Video (I99I), which has been frequently read in a biographical key as a portrait of the initial GAINAX members and even as a manifesto or 'discourse' representing otaku culture and even anime (Lamarre 2004 I 56). However, while Hideaki Anno and Toshio Okada self-identify as otaku (Horn I996: para. 8), other members of the initial Studio GAINAX tend to distance themselves from that identity label (Manry \& Yamaga 20I0: para. 56). Actually, some scholars also deny the otaku element in GAINAX products. What Otaku no Video shows is the need for challenging the fictional identities of otaku 'fabricated by media' (Shen 20I 5: 83).

At the time of EVA's first broadcast, the availability of anime titles overseas was determined by the different circumstances of each 
national market. EVA found its public among adolescents and fans of SF, but since then it has been presented as the flagship of anime culture. At that moment, the market was still dominated by OVAs, or limited series and movies distributed in domestic video formats, before the companies began to work with longer series. Even after the international success of products such as EVA, the anime production committees were promoting their products adopting a low-risk approach. These strategies were intended to build an image that would eventually help the successful sale of the rest of the product cohort. Anime historian Jonathan Clements points out how festival advertising tended to homogenize manga and anime audiences:

I still fondly remember how Evangelion and Escaflowne, in their original PR, were made to sound exactly the same. If left to their own devices, many marketers will be happy with 'Boy gets Robot in a heart-warming masterpiece with several girls who are demure and nice and childhood sweetheart who is a mysterious girl'. (Clements 20I0: 66)

When the catalogue of TV series increased, satellite and cablebased broadcasters started to include this offer in the form of thematic channels. In response to new audiences, keen on all forms of Japanese visual culture, specialized magazines appeared (AnimeLand, Newtype USA, Otaku US, etc.). In many cases, manga and anime were at first only an extra, introduced in magazines dedicated to comics or video games, that is, markets expected to share audiences with anime. A transition can be seen in the video market just like in the publishing market, whereby anime moves away from using generic labels derived from Western cinema and literature to develop its own vocabulary. In the beginning, manga was considered a genre by the publishing market, due to the small number of titles and the limited diversity of their catalogue. The same applied to the anime market. The local video market was monopolized by a small number of distributors employing 'manga' and 'anime' stamps for a heterogeneous collection of titles that prioritized contents perceived as 
subversive for non-Japanese audiences (Hernández-Pérez, Corstorphine \& Stephens 20I7).

At that time, many scholarly sources disregarded demographic labels in their discussion of genre (Bryce \& Davis 2010: 34; Drazen 2003; Poitras 200I; Richmond 2009). Thematic categories derived from cinema or literature such as drama, noir, SF and comedy predominated, attending to iconographic elements, such as mecha in anime.

As we have seen through different approaches to genre, objects or motifs represented within narratives (i.e., the most evident or iconographic elements) are perhaps the most intuitive way of establishing classifications. We tend to complement those casual categories with the similarity to other texts. When working on iconography, those references are linked in terms of architextuality, a common term for previous sets of text or traditions (mecha anime, SF). Another way would be to employ natural language which ultimately can describe not only feelings and emotional assessments of the experience with the product, but also motivations behind its consumption (a 'casual' shōnen, a reference in this genre, etc.).

In the last 30 years, media classification has become increasingly sophisticated with the development of the so-called social web and the integration of folksonomies, or collaborative classifications, in the construction of databases and recommendation systems. In the context of web 2.0, users are both the main resource and mechanism for content classification and indexing. Part of this evolution has been reflected in media platforms such as Netflix or, the most anime-specific streaming service, Crunchyroll, which include these tag-based recommendation systems.

Although these classification systems share architectures, they differ in their resulting lists of tags or terms, due to the different roles that communities have in their construction and maintenance. Interestingly, virtual communities with a large fanbase, and also some streaming platforms, seem to share a predilection for the demographic 
labels used in the Japanese market. On Crunchyroll, for example, we find the use of shonen [sic] and shojo [sic], along with definitions related to other media (romance, SF, thriller, mystery, etc.) or fandomderived definitions (like ecchi $i^{8}$ ). The recommendation systems, on the other hand, function as more inclusive information structures, employing terms provided by users, practically inseparable from tagging behavior. Members of a virtual community often recycle categories proposed by digital curators and even create their own descriptions of a cultural artifact when submitting information to the system, such as 'Japanese animated series' or 'Japanese animated films.'

Platforms such as Netflix or Crunchyroll present closed systems that do not allow for user curation, directing consumption through the algorithms responsible for their own recommendations systems, as well as their own indexing systems. This selection of categories responds to editorial decisions. Therefore, political discourse uses ideology (Altman I999) in the very same way that genres are curated. When referring to the EVA anime series and movies, Netflix labels them under the categories 'Anime Action,' 'Sci-Fi \& Fantasy Anime' and 'Japanese TV Programmes,' but it also uses other tags such as 'cyberpunk' and 'exciting.'

Previous studies have resorted to content analysis to understand how audiences conceptualize anime. A study of the recommendations on Anime News Network (Cho et al. 2018) noted is features commonly used in the recommendation system, including Work, Theme, Genre, (Target) Audience and Mood, while other features such as Artwork/ Visual Style, Audio Style and Language were found to be used less often. Genre categorizations in these databases are usually employed in combination with a list of similar products obtained from the platform's catalogue metadata. Thus, this suggests that the similarities among products (same director, same production/release date, same mood, etc.) may be regarded as a better predictor of user behavior than shared conceptualizations of a particular genre and/or artistic tradition.
8. Ecchi-derived from erotic (erochikku)—can be translated as sexy, naughty or dirty. It is a common label used to describe light and playful sexual plots within anime or manga. 
9. Referring to aspects of the product that can be frightening or disturbing for some audiences.

ıо. Short for 'Your Mileage May Vary.' These sections collect information about those aspects in which fan audiences may differ in their appreciation of the product.

II. This stands for 'Wild Mass Guess,' or speculations about the meaning of a given aspect of the narrative.
This fact may explain the popularity of online repositories such as TVtropes.org, a site that collects a large myriad of definitions and includes thousands of categories for stylistic, narrative and even authorial classifications of anime. In the EVA entry at TVtropes, the available information is presented in a similar way to any Wiki site or collaborative encyclopedia, where the anime series page links to another one containing information about the franchise as a whole. Therefore, these pages provide a good example of aggregation. While tags like 'anime' or 'franchise' could be part of other ontological representations such as library databases, the same metadata structure also includes appreciations (awesome, HoYay, 'TearJerke,' 'Nightmare Fuel,'9 'YMMV,'10 etc.), or other related information ('Quotes,' 'AwesomeMusic,' 'FanWorks,' 'Videos,' 'Trivia,' 'WMG,'11 'Pantheon' or character's genealogy). Moreover, when the provided material links to other pages-such as those with the characters from the expanded world-setting - the categorization of such information may include many other intertextualities that combine commentaries with actual facts. For example, the 'ideal casting' for a live-action production based on the series may include actual actors who had been considered for the same role in the past.

Cultural databases are a common construct to articulate the idea that meanings within narrative do not need to be presented in the form of cohesive structures, but are rather acquired in interaction with audiences. When it comes to anime, post-structuralist theoreticians like Azuma (2009) have proposed the use of these cultural databases to explain the disappearance of 'grand narratives,' a figure that works as synonymous of the more usual discourses in the context of post-structuralist and post-modernist philosophies. They also claim that databases or small narratives not only explain the cultural success of moe consumption, but are also the way in which modern 'readers' will engage with texts. EVA's case is particularly relevant for Azuma's cultural theory. The author examines the use of EVA 
as a grand narrative, accepting classical readings in relation to genre in terms of dystopian narrative or environmentalist rhetoric (Azuma 2009: 30-33). Otherwise, he uses the character of Rei Ayanami as a prototype of the small narratives in its $m o e^{12}$ consumption (ibid.: 37 ) when it is presented de-contextualised in other parallel narratives such as video games or even non-narrative media, including merchandising. Azuma's otaku database (2009) reflects a process of structured induction based on the familiarity within exemplars (i.e., characters with a shy behavior, blue hair, an eye patch, etc.).

On the contrary, databases such as TVtropes are not articulated to any research narrative. Those are constructed as an effect of social interaction that shadows the need for intellectual definition, and subsequently (re)model after many subjectivities from fan community members. These databases are, perhaps, useful as a repository of unstructured collective data, but not in order to construct articulated thought.

We employ genres in our daily life and communication, but we also rely on other ways to classify and recommend products. Can those be non-curated databases of interest for the study of anime? All the communities I have examined-including curated databases, recommendation systems, streaming platforms and folksonomies-differ in the way in which they establish anime genres, as a consequence of the use of different terminologies. Although genres are supposed to be shared constructions, it is also argued that ordinary language and community participation can offer insights to guide genre classification (Swales I990: 220). Folksonomies can therefore help the definition of texts, as well as modes of consumption, since their formulation can also be the answer to a common intellectual problem. In fact, this seems to be the case with Wikipedia, as the global site has proven to be quite efficient in terms of construction and maintenance costs, as well as impervious to fake information (McDowell \& Vetter 2020).
I2. Moe refers to the affective relation between fan audiences and anime objects. 


\section{Conclusions: The Shifting Nature of Genres in EVA}

The problem behind soft approaches to genre is that the concept is used just as a descriptor without any critical thought about its actual implications, ultimately undermining the concept of genre itself. Genre becomes an introductory framework, challenged by case studies. In this chapter, I discussed previous approaches to genre-including the role that audiences, textual properties and media have in the construction of genre concept-in order to address EVA's case.

Nowadays, anime tends to be considered not as a genre, but as a medium defined by its material traits, rather than focusing on its content or target audience. However, this is but one way of considering genre categories. Instead, it would be fitting to think of anime narratives as a genre colony (or a family of genres) that can still be defined as a medium. Consequently, genre becomes a way to define qualities within the anime medium.

Such an approach to Anime Studies would allow the inclusion of an iconographic perspective, in which an indeterminate number of identifiable objects represents a genre, and eventually enable multiple undefined hybridizations. Ultimately, this provides a transmedia perspective of 'genre,' in which two or more media share aesthetic or material qualities, and where the genre becomes an intermedial exchange space.

It has been noted that Film (Wood 2008: 46) and Media Studies tend to assume an opposite approach: genre vs. authorship. In the case of EVA, the discussion of genre is defined by its textual characteristics (syntactic and semantic), but also by the author, as he is responsible for the main creative choices. Tropes and formulas may establish a relationship between EVA and various genres, including SF and dystopian/post-apocalyptic narratives. However, the identification of semata (or meaningful units) is not enough for a genre definition. In this regard, it is worth mentioning how through both semantic and syntactic approaches, EVA can be related to exotic influences, such as the Judeo-Christian iconography or the conventions in apocalyptic 
narratives, but also to established traditions within anime, including mecha and tokatsu genres.

\section{References}

Altman, R. (1999). Film/genre. London: BFI Publishing.

Animerica (1996). Hideaki Anno's Roundtable Discussion. Excerpts from a Roundtable Disccussion with Hideaki Anno at the Anime Expo '96 Convention, Animerica, 4(9), 27. Retrieved from: http://web.archive.org /web/2002 I 208 I 23622/http://masterwork.animemedia.com/Evange lion/anno.html

Anno, H. (1996a). About Neon Genesis Evangelion. Newtype, November, 20-23. Retrieved from: https://www.gwern.net/otaku (translated by Miyako Graham/Protoculture Addicts)

. (1996b). Interview with Hideaki Anno. Newtype, June. Retrieved from: https://www.gwern.net/docs/eva/ı 996-newtype-anno-interview (translated by Gwern Branwen)

\& Higuchi, S. (2013). Nihon tokusatsu no kako, genzai, soshite mirai o fukan shite. Commissioned by Japan's Agency for Cultural Affairs Manga, Animation, Games, and Media Art Information Bureau. Tokyo: Mori Building Co., Ltd. Retrieved from: https://mediag.bunka .go.jp/projects/project/images/tokusatsu-20I3.pdf

Azuma, H. (2009). Otaku: Japan's Database Animals. Minneapolis, MN: University of Minnesota Press. (Introduction and translation by J. E. Abel and S. Kono)

(20I6). Anime or Something Like it: Neon Genesis Evangelion. Intercommunication, I 8. Retrieved from: https://www.ntticc.or.jp /pub/ic_mag/ico I8/intercity/higashi_E.html

Bhatia, V. K. (I 999). Integrating Products, Processes, Purposes and Participants in Professional Writing. In C. N. Candlin and K. Hyland (eds.), Writing: Texts, Processes and Practices (pp. 2I-39). London: Routledge.

Bolton, C. \& Csicsery-Ronay Jr, I. (2007). Robot Ghosts and Wired Dreams: Japanese Science Fiction from Origins to Anime. Minneapolis, MN: University of Minnesota Press. 
Bryce, M. \& Davis, J. (2010). An Overview of Manga Genres. In T. Johnson-Woods (ed.), Manga: An Anthology of Global and Cultural Perspectives (pp. 17-33). New York: Continuum International.

Buscombe, E. (I970). The Idea of Genre in the American Cinema. Screen, II (2), 33-45.

Cavallaro, D. (2009). The Art of Studio Gainax: Experimentation, Style and Innovation at the Leading Edge of Anime. Jefferson, NC: McFarland.

Cawelti, J. G. (1976). Adventure, Mystery, and Romance: Formula Stories as Art and Popular Culture. Chicago, IL: University of Chicago Press.

Chapman, P. (20I7). Hideaki Anno Hosts Tokusatsu History Panel in Shinjuku in March. Crunchyroll. Retrieved from: https://www.crunch yroll.com/en-gb/anime-news/20I 7/02/25-I/hideaki-anno-hosts-toku satsu-history-panel-in-shinjuku-in-march

Cho, H., Schmalz, M. L., Keating, S. A. \& Lee, J. H. (20 I 8). Analyzing Anime Users' Online Forum Queries for Recommendation Using Content Analysis. Journal of Documentation, 2. DOI: https://doi.org /IO.I IO8/jd-O8-2OI7-OI 22

Clements, J. (2010). Schoolgirl Milky Crisis: Adventures in the Anime and MangaTtrade. London: Titan Books.

Denison, R. (2015). Anime: A Critical Introduction. London: Bloomsbury Academic.

Derrida, J. \& Ronnell, A. (1980). The Law of Genre. Critical Inquiry, $7(\mathrm{I}), 55-8 \mathrm{I}$.

DiTommaso, L. (20I4). Apocalypticism and Popular Culture. In J. J. Collins (ed.), The Oxford Handbook of Apocalyptic Literature (pp. 473-5 I0). Oxford: Oxford University Press.

Drazen, P. (2003). Anime Explosion! The What? Why? \& Wow! of Japanese Animation. Berkeley, CA: Stone Bridge Press.

Dyer, R. (1998). Stars. London: BFI.

Feuer, J. (r992). Genre Study and Television. In R. C. Allen (ed.), Channels of Discourse, Reassembled (pp. I38-160). Chapel Hill, NC: University of North Carolina Press. 
GAINAX (1997). Neon Genesis Evangelion Move!! In Neon Genesis Evangelion Newtype 100\% Collection (pp. 85-89). Tokyo: Kadokawa Shoten. In EvaWiki (2020), Neon Genesis Evangelion Proposal. Retrieved from: https://wiki.evageeks.org/Neon_Genesis_Evangelion _Proposal

Genette, G. (1992). The Architext: An Introduction. Berkeley, CA: University of California Press.

Giner, P. (1997). Interview Hideaki Anno. AnimeLand, 32, I9-2I. Retrieved from: https://www.gwern.net/docs/eva/ı997-animeland-may -hideakianno-interview.pdf

Grant, B. K. (2007). Film Genre: From Iconography to Ideology. London: Wallflower.

Hernández-Pérez, M. (2016). Animation, Branding and Authorship in the Construction of the 'Anti-Disney' Ethos: Hayao Miyazaki's Works and Persona through Disney Film Criticism. animation. an interdisciplinary journal, II(3), 297-3 I3. DOI: https://doi.org/IO.I I77/I 7468 477 I 6660684

., Corstorphine, K. \& Stephens, D. (2017). Cartoons vs. Manga

Movies: A Brief History of Anime in the UK. Mutual Images, 2(I), I-39. Retrieved from: DOI: https://doi.org/IO.32926/2017.2.HER.carto

Hikawa, R. (ed.) (2013). Japanese Animation Guide: The History of Robot Anime. Tokyo: Mori Building Company, Ltd. https://mediag .bunka.go.jp/projects/project/images/JapaneseAnimationGuide.pdf

Horn, C. (I996). "Return of the Otaking." Toshio Okada at Anime America I 996 (Written Statements). Retrieved from: https://web .archive.org/web/200003050I 2502/http://www.j-pop.com/anime /archive/feature/o4_gal_999/otaking2.html

Hu, T. Y. G. (2010). Frames of Anime: Culture and Image-Building. Hong Kong: Hong Kong University Press.

Jenkins, H. (r992). "Strangers No More, We Sing”: Filking and the Social Construction of the SF Fan Community. In L. A. Lewis (ed.), The Adoring Audience: Fan Culture and Popular Media (pp. 208-236). London: Routledge. 
Khara, Studio (2006) Kabushikigaisha karā [Studio Khara History]. Retrieved from: http://www.khara.co.jp/history/

Lamarre, T. (2004). An Introduction to Otaku Movement. EnterText, $4(\mathrm{I})$, I 5 I-I 87.

Manry, G. \& Yamaga, H. (20Iо). Interview: Gainax's Hiroyuki Yamaga. Anime News Network. Retrieved from: https://www.animenewsnet work.com/interview/2010-06-03/interview-gainax-hiroyuki-yamaga

McDowell, Z. J. \& Vetter, M. A. (2020). It Takes a Village to Combat a Fake News Army: Wikipedia's Community and Policies for Information Literacy. Social Media + Society, July-September, I-I3. Retrieved from: DOI: https://doi.org/IO.I I 77/2056305 I 209 37309

Mittell, J. (200I). A Cultural Approach to Television Genre Theory. Cinema Journal, 40(3), 3-24. DOI: https://doi.org/I0.2307/I350192

Mousoutzanis, A. (2009). Apocalyptic SF. In M. Bould, A. Butler, A. Roberts and S. Vint (eds.), The Routledge Companion to Science Fiction (pp. 458-462). London: Routledge.

Nagai, G. and Dynamic Productions (I999). Extracts from Devilman Tabulae Anatomicae Kaitai Shinsho Art Book. In Gwern Branwen (ed.) (2010), Neon Genesis Evangelion Source Anthology. Retrieved from: https://www.gwern.net/otaku

Napier, S. J. (1993). Panic Sites: The Japanese Imagination of Disaster from Godzilla to Akira. Journal of Japanese Studies, I9(2), 327-35 I. . (200I). Anime from Akira to Princess Mononoke: Experiencing Contemporary Japanese Animation. New York: Palgrave Macmillan.

Orbaugh, S. (2009). Manga and Anime. In M. Bould, A. Butler, A. Roberts and S. Vint (eds.), The Routledge Companion to Science Fiction (pp. I I 2-I 22). London: Routledge.

Ortega, M. (2007). My Father, He Killed Me; My Mother, She Ate Me: Self, Desire, Engendering, and the Mother in Neon Genesis Evangelion. Mechademia, 2(I), 216-232.

Poitras, G. (200I). Anime Essentials: Everything a Fan Needs to Know. Berkeley, CA: Stone Bridge Press. 
Richmond, S. (2009). The Rough Guide to Anime: Japan's Finest from Ghibli to Gankutsuō. London: Rough Guides.

Ryan, M.-L. (2004). Introduction. In M.-L. Ryan (ed.), Narrative across Media: The Languages of Storytelling (pp. I-40). Lincoln, NE: University of Nebraska Press.

Schatz, T. (198I). Hollywood Genres: Formula, Filmmaking, and the Studio System. New York: Random House.

Shen, L. F. (2015). Traversing Otaku Fantasy: Representation of the Otaku Subject, Gaze and Fantasy in Otaku no Video. In P. W. Galbraith, T. H. Kam and B.-O. Kamm (eds.), Debating Otaku in Contemporary Japan: Historical Perspectives and New Horizons (pp. 73-88). London: Bloomsbury Academic.

Smith, C. (I993). The Rediscovery of Man: The Complete Short Science Fiction of Cordwainer Smith. Framingham, MA: NESFA Press.

Stewart-Ahn, A. (2019). Neverending Evangelion. How Hideaki Anno Turned Obsessions and Depression into an Anime Phenomenon. Polygon. Retrieved from: https://www.polygon.com/2019/6/I9/1 8683634 /neon-genesis-evangelion-hideaki-anno-depression-shinji-anime-char acters-movies

Suvin, D. (1972). On the Poetics of the SF Genre. College English, 34(3), $372-382$.

. (1979). Metamorphoses of Science Fiction: On the Poetics and History of a Literary Genre. London: Yale University Press.

Swales, J. (I990). Genre Analysis: English in Academic and Research Settings. Cambridge: Cambridge University Press.

Takeda, Y. (2005). The Notenki Memoirs. Studio GAINAX and the Men Who Created Evangelion. Tokyo: Wani Books. (Translated by ADV Manga)

Tatsumi, T. \& Bolton, C. (2008). Gundam and the Future of Japanoid Art. Mechademia, 3, I9I-I98.

Thomas, J. B. (2012). Drawing on Tradition: Manga, Anime, and Religion in Contemporary Japan. Honolulu, HI: University of Hawaii Press. 
Tsurumaki, K. \& Thomas, O. (200I). Amusing Himself to Death (Interview with Kazuya Tsurumaki). Akadot. Retrieved from: https:// web.archive.org/web/20070806063455/http://www.akadot.com/article .php? $\mathrm{a}=\mathrm{I} 82$

Ueno, T. (2006). Kurenai no metalsuits, "Anime to wa nani ka/What is animation." Mechademia, I, I I I-I I 8. DOI: https://doi.org/IO.I353 /mec.0.005 5. (Translated by M. Arnold)

Watanabe, K. \& Otsuki, T. (2006), Interview with Toshmichi Otsuki, Mainichi Manga Town. Retrieved from: https://wiki.evageeks.org /Statements_by_Evangelion_Staff

Watanabe, M. (200I). Imagery and War in Japan: I995. In T. Fujitani, G. M. White and L. Yoneyama (eds.), Perilous Memories: The AsiaPacific War(s) (pp. I 20-I 5I). Durham, NC and London: Duke University Press. doi:I0.2307/j.ctvi I 3 Iczf

Wong, W. S. (2010). Globalizing Manga: From Japan to Hong Kong and Beyond. In T. Johnson-Woods (ed.), Manga: An Anthology of Global and Cultural Perspectives (pp. 332-350). New York: Continuum International.

Wood, R. (2008). Ideology, Genre, Auteur. In Auteurs and Authorship: A Film Reader (pp. 84-92). Maldwell: Blackwell Publishing.

Yamaguchi, Y. (2004). Nihon no anime zenshi. Tokyo: Ten Books. 